\title{
Myocardial oxygen consumption in aortic valve disease with and without left ventricular dysfunction
}

\author{
Juerg Schwitter, Franz R Eberli, Manfred Ritter, Marko Turina, Hans P Krayenbuehl
}

\begin{abstract}
Objective-To assess whether and to what extent myocardial oxygen consumption is modified by hypertrophy and alterations in contractility in patients with aortic valve disease and to evaluate the influence of regression of left ventricular hypertrophy and improvement of contractility on myocardial oxygen consumption after successful aortic valve replacement.
\end{abstract}

Design-A cohort analytical study to investigate the influence of the "explanatory" variables of myocardial oxygen consumption by multiple regression analysis. A comparison of myocardial oxygen consumption in preoperative patients with that after operation in a group with comparable severity of aortic valve disease before operation (analysis of covariance).

Patients-In six controls and in 43 patients with aortic valve disease and normal coronary arteries standard haemodynamic variables were measured, left ventricular biplane cineangiography performed, and coronary sinus blood flow measured by thermodilution. The patients were divided into three groups: 19 preoperative patients with normal ejection fraction ( $\geqslant 57 \%$ ) (group 1); nine preoperative patients with reduced ejection fraction $(<57 \%)$ (group 2); 16 postoperative patients (one with preoperative and postoperative measurements (group 3). Postoperative evaluation was performed 12-51 months after surgery.

Main outcome measurementsMyocardial oxygen consumption/100 g left ventricular muscle mass and its suspected "explanatory" variables-that is, peak systolic left ventricular circumferential wall stress, heart rate, contractility (assessed by left ventricular ejection fraction), and left ventricular muscle mass index.

Results-Multiple regression analysis showed that the product of peak systolic stress and heart rate $(p<0.0001)$ and ejection fraction $(p<0.03)$ were positively correlated with myocardial oxygen consumption/100 $\mathrm{g}$ and that left ventricular muscle mass index $(p<0.002)$ was negatively correlated with myocardial oxygen consumption $/ 100 \mathrm{~g}(\mathbf{r}=0.72 ; n=$ 50 measurements). Myocardial oxygen consumption per $100 \mathrm{~g}$ at a given stress- rate product was higher in the controls than in group 1 (hypertrophied ventricles with normal ejection fraction) and was also higher in group 1 than in group 2 (hypertrophied ventricles with reduced ejection fraction). In a subgroup of the postoperative patients with complete regression of hypertrophy and normalisation of contractility, myocardial oxygen consumption per $100 \mathrm{~g}$ at a given stress-rate product was indistinguishable from that in controls.

Conclusions-When the actual stressrate product was used as an index of overall left ventricular performance the results suggested that mechanical efficiency was increased in hypertrophied ventricles especially when contractility was decreased. These changes in mechanical efficiency seemed to be reversible during the postoperative course when muscle mass and contractility returned to normal.

The oxygen consumption of the human heart depends upon various factors-mainly systolic tension development or systolic wall stress, heart rate, and contractility. ${ }^{1-3}$ Of lesser importance are the oxygen costs associated with shortening and the basal resting metabolism. $^{3} \quad$ These determinants of myocardial oxygen consumption are valid for the normal heart at rest and during acute changes of loading or inotropism. But it is not known whether and to what extent the degree and appropriateness of ventricular hypertrophy and myocardial contractility, or both, influence and modify the relations between the myocardial oxygen consumption and its classic determinants in the chronically overloaded heart. Earlier studies showed alterations in coronary blood flow and the myocardial oxygen consumption in cardiac hypertrophy, but many of these studies involved animal models. ${ }^{4-6}$ The present study was performed in patients in whom left ventricular hypertrophy had developed in response to the longstanding haemodynamic burden of isolated aortic stenosis or insufficiency or a combined lesion. The patient population was divided into two groups-one with left ventricular dysfunction and one without. We also examined a third group of patients with regression of cardiac hypertrophy 26 months after successful aortic valve replacement.

The three objectives of the present investigation were to evaluate the influence of loading 
conditions (represented by the product of heart rate and peak systolic stress (stress-rate product)) on myocardial oxygen consumption per $100 \mathrm{~g}$ in hypertrophied hearts compared with the normal heart; to assess the influence of cardiac contractility on myocardial oxygen consumption per $100 \mathrm{~g}$; and to evaluate whether the postoperative regression of left ventricular hypertrophy modified the relation between the myocardial oxygen consumption per $100 \mathrm{~g}$ and its haemodynamic determinants.

\section{Patients and methods \\ PATIENTS}

Six patients (four men and two women) with normal left ventricular function who underwent left heart catheterisation for atypical chest pain and had no coronary artery disease served as controls. Coronary flow reserve after dipyridamole was determined by thermodilution and was normal in all of them (range $2 \cdot 18-4 \cdot 30$, mean (SD) $2.9(0.9)$ : normal values $1.74-4.30$, $2.54(1.02))^{7}$. None of the controls was being treated with drugs or had a history of arterial hypertension; values of fasting plasma glucose and cholesterol were in the normal range.

Thirty patients (21 men, nine women; mean (SD) age 61 (7) years) had aortic stenosis and were in New York Heart Association (NYHA) class 2.2 (SD 0.4). The mean (SD) systolic pressure gradient across the aortic valve was 71 (16) $\mathrm{mm} \mathrm{Hg}$. The mean (SD) aortic valve area was $0.7(0.17) \mathrm{cm}^{2}$, range $0.3-1.0 \mathrm{~cm}^{2}$ (including six patients with combined aortic valve disease and predominant aortic stenosis defined as aortic valve area $\leqslant 1.0 \mathrm{~cm}^{2}$ ). Thirteen patients, all men, (age 51 (8) years) had aortic insufficiency and were in NYHA class 2.0 (SD 0.4). The mean (SD) aortic regurgitation fraction determined by thermodilution was 54 (10)\% (range $37-75 \%$ ). Three of the 13 patients had combined aortic valve disease with predominant insufficiency defined as aortic valve area $>1.0 \mathrm{~cm}^{2}$. All patients had normal coronary arteries by selective coronary arteriography.

Twenty eight of the 43 patients with aortic valve disease were studied preoperatively. In four of the six controls and in the 16 postoperative patients measurements of coronary sinus blood flow and myocardial oxygen consumption were performed at an ambulatory right heart catheterisation. One patient was studied both before and after operation.

\section{PATIENT GROUPS}

Patients were divided in groups as follows: controls, six, with normal ejection fraction $(\geqslant 57 \%)^{8}$; group 1, 19 patients with aortic stenosis or insufficiency and normal ejection fraction; group 2, nine patients with aortic stenosis or insufficiency and reduced ejection fraction $(<57 \%)$; group 3, 16 patients after successful aortic valve replacement for aortic stenosis or insufficiency. Group 3 was further divided into: group $3 A$, six patients with complete postoperative regression of left ven- tricular hypertrophy (normal left ventricular muscle mass index $\leqslant 117 \mathrm{~g} / \mathrm{m}^{2}$ ) and an ejection fraction within the range for the controls (63-77\%); and group $3 B, 10$ patients with incomplete regression of left ventricular hypertrophy (left ventricular muscle mass index $>117 \mathrm{~g} / \mathrm{m}^{2}, \mathrm{n}=4$ ) and/or an ejection fraction in the low normal range $(57-62 \%, n=6)$. Group 2 patients were considered to have depressed contractility because their ejection fraction was reduced in the presence of an afterload and preload that were not different from those in the controls.

Patients in groups 1,2 , and 3 in the preoperative state did not differ with regard to the NYHA class (table 1). In group 3 two of 16 patients had mild dyspnoea during exercise (NYHA class I-II). In group 1 two patients were taking digitalis, two nitrates, two angiotensin converting enzyme inhibitors, one diuretics, and one calcium antagonists. In group 2 three patients were taking digitalis, three diuretics, three calcium antagonists, and two nitrates. In group 3 five patients were taking calcium antagonists, two digitalis, and two diuretics. All drugs were stopped at least 24 hours before catheterisation.

\section{CATHETERISATION AND CINEANGIOGRAPHY}

The controls and all 43 preoperative patients underwent right and left heart catheterisation in the fasting state. Informed consent was obtained from all patients. Premedication consisted of oral chlordiazepoxide (10 mg) administered an hour before the procedure. Right sided pressures and the aortic pressure were measured with a 7F Cournand catheter and a fluid filled $8 \mathrm{~F}$ pigtail catheter respectively. In patients with aortic valve disease left ventricular pressure was obtained via a transseptally inserted $8.5 \mathrm{~F}$ Brockenbrough catheter. A peripheral lead of the electrocardiogram was recorded at the same time as the pressures. Left ventricular cineangiography was performed in the right $\left(30^{\circ}\right)$ and left $\left(60^{\circ}\right)$ anterior oblique projections.

Biplane left ventricular volumes were determined according to the area-length method. ${ }^{10}$ Left ventricular end diastolic wall thickness (cm), muscle mass (g), and muscle mass index $\left(\mathrm{g} / \mathrm{m}^{2}\right)$ were measured according to the technique of Rackley et al. ${ }^{11}$ The left ventricular end diastolic circumferential wall stress was calculated according to the formula of Sandler and Dodge. ${ }^{12}$ Peak systolic wall stress $\left(S_{\text {peak }}\right)$ was estimated at a point one third through ejection as proposed by Gaasch et al. ${ }^{13}$ In the 16 postoperative patients (group 3 ) an ambulatory right heart catheterisation was performed. A $8 \mathrm{~F}$ pigtail catheter was inserted into the pulmonary artery. Biplane left ventricular angiograms were obtained after injection of 50$60 \mathrm{ml}$ of Iopamiro 370 (iopamidol and trometamol) into the pulmonary artery. In these 16 postoperative patients and in four controls in whom ambulatory coronary sinus blood flow was measured 7-17 days after diagnostic coronary arteriography left ventricular end diastolic pressure was replaced by mean pulmonary wedge pressure, left ventricular 
tricular systolic pressure was taken as systolic cuff pressure, and mean aortic pressure was calculated as diastolic cuff pressure plus one third of the pulse pressure amplitude. In the postoperative patients the pressure gradient across the aortic valve prosthesis was ignored.

\section{CORONARY BLOOD FLOW MEASUREMENTS}

Coronary sinus blood flow was measured after the diagnostic catheterisation in 28 preoperative patients with aortic valve disease and in two controls. In four controls and the 16 postoperative patients (one of whom had both preoperative and postoperative evaluation) measurement of coronary sinus blood flow was performed on an ambulatory basis with right heart catheterisation-in the postoperative patients this was a mean of 26 months (range 12-52 months) after successful aortic valve replacement. Total coronary sinus outflow was measured by the coronary sinus thermodilution technique. ${ }^{714}$ A 7F thermodilution catheter (CCS-7U-90A or B, Webster Laboratory, Altadena, California) was introduced from the right femoral vein or in a few cases from the right cubital vein and advanced into the coronary sinus and the dilution thermistor was placed $2 \mathrm{~cm}$ from the orifice. The position was checked by injection of small amounts of contrast dye. Injection of cold saline into the superior vena cava did not change the temperature curve of the thermistor in the coronary sinus. ${ }^{15}$ The signals of the external (mixing temperature of blood and saline) and internal (temperature of the injected saline) thermistors were recorded on a oscillograph (Electronics for Medicine VR-12) at a paper speed of $5 \mathrm{~mm} / \mathrm{s}$. Saline at room temperature was infused through the thermodilution catheter at a rate of $50 \mathrm{ml} / \mathrm{min}$ and coronary sinus blood flow $(\mathrm{ml} / \mathrm{min}$ ) was calculated according to the formula of Ganz et al. ${ }^{14}$ Coronary resistance (CR) $\left(\mathrm{mm} \mathrm{Hg}-\mathrm{min} \mathrm{ml}^{-1}\right.$ ) was calculated according to the following equation:

$$
\mathrm{CR}=\frac{\mathrm{MAP}-\mathrm{CSP}}{\mathrm{CSBF}}
$$

where MAP equals mean aortic pressure (mm Hg); CSP, mean coronary sinus pressure $(\mathrm{mm} \mathrm{Hg})$; and CSBF, coronary sinus blood flow $(\mathrm{ml} / \mathrm{min})$. Arterial and coronary sinus oxygen saturation were measured by an Instrumentation Laboratory System 1302 blood gas analyser (Nanolab AG, CH-Schlieren). Myocardial oxygen consumption ( $\mathrm{ml} / \mathrm{min}$ ) was determined as the product of the arteriocoronary sinus oxygen difference (vol\%) and the coronary sinus blood flow. Coronary sinus blood flow, coronary resistance, and the myocardial oxygen consumption were standardised for $100 \mathrm{~g}$ of left ventricular muscle mass. Because injection of contrast can alter coronary dynamies, ${ }^{16}$ coronary sinus blood flow was not recorded within 20 minutes of an injection of contrast agent.

In controls coronary sinus outflow was determined at rest as well as after infusion of dipyridamole $(0.5 \mathrm{mg} / \mathrm{kg}$ body weight) over 15 minutes. The coronary flow ratio (coronary flow reserve) was calculated as coronary sinus blood flow after dipyridamole infusion divided by the blood flow at rest. ${ }^{7}$

\section{STATISTICAL ANALYSIS}

We used a one way analysis of variance to compare data from the controls and the patients from groups 1,2 , and 3 . If the analysis showed an overall significant $p$ value $(p<0.05)$ we used Scheffe's test to compare all pairs of means. When only two groups were compared we used the unpaired Student's $t$ test. Comparisons between pre and post operative data for group 3 patients were performed by the paired Student's $t$ test.

Initially differences in myocardial oxygen consumption between the four groups were compared by analysis of covariance ${ }^{17}$ with the stress-rate product as a covariate, using the correction for multiple tests by Bonferroni. In a second step "explanatory" variables were regarded as continuous rather than categorical and multiple regressions were performed. In all tables values are given as mean (SD).

\section{Results}

The four patient groups did not differ in age (49, $59,58,57$ years) and body surface area $(1.86$, $1.79,1.82,1.90 \mathrm{~m}^{2}$ ). None of the patients was anaemic and the haemoglobin concentration was similar in the four groups.

\section{HAEMODYNAMICS AND ANGIOGRAPHIC DATA IN} PREOPERATIVE PATIENTS AND CONTROLS (TABLES 1 AND 2)

In the preoperative patients with predominant aortic stenosis and left ventricular dysfunction (subset of group 2) the aortic valve area was slightly smaller $(p<0.05)$ than in the patients without left ventricular dysfunction (subset of group 1). The mean aortic pressure gradient was similar.

The left ventricular muscle mass index was higher in the preoperative patients with left ventricular dysfunction (group 2) and without (group 1) than in the controls and the postoperative patients (group 3). The left ventricular end diastolic wall thickness was similar in patients in groups 1 and 2 but it was higher than in the controls and group 3. The left ventricular end diastolic volume index in group 2 was larger than in the controls and postoperative patients; there was no difference between patients in groups 1 and 2 . Left ventricular systolic pressure was higher in groups 1 and 2 than in the controls. In the postoperative patients left ventricular end diastolic pressure was lower than in the groups 1 and 2 patients but did not differ from that in the controls. There was no difference in peak systolic stress between controls and patients with aortic valve disease with left ventricular dysfunction and without. Peak systolic stress was lower in the postoperative group than in groups 1 and 2 . The end diastolic circumferential stress was higher in the group 2 patients than in groups 1 and 3 . The cardiac index was lower in group 2 than in the controls. 
Table 1 Preoperative data for groups 1,2, and 3

\begin{tabular}{|c|c|c|c|c|c|c|c|}
\hline Group & $n$ & $\begin{array}{l}\text { Age }(y) \\
(\text { mean }(S D)(\text { range }))\end{array}$ & $\begin{array}{l}\text { NYHA class } \\
(\text { mean }(S D)(\text { range }))\end{array}$ & $\begin{array}{l}\text { Mean } A V \text { gradient } \\
(\text { mm } H g) \\
(\text { mean }(S D) \text { range }))\end{array}$ & $\begin{array}{l}A V A\left(\mathrm{~cm}^{2}\right) \\
(\text { mean }(S D) \text { range }))\end{array}$ & $\begin{array}{l}f_{a 0}(\%) \\
(\text { mean }(S D) \text { range }))\end{array}$ & $\begin{array}{l}f_{\text {mi }} \ddagger(\%) \\
(\text { mean }(S D) \text { range }))\end{array}$ \\
\hline Controls & 6 & $49(10)(30-58)$ & - & - & - & - & - \\
\hline $\begin{array}{l}\text { Group 1: } \\
\text { AS } \\
\text { AI }\end{array}$ & $\begin{array}{r}16 \\
3\end{array}$ & $\begin{array}{l}61(6)(49-73) \\
46(8)(39-54)\end{array}$ & $\begin{array}{l}2.1(0.4)(1.5-3) \\
1.8(0.3)(1.5-2)\end{array}$ & $\begin{array}{l}73(16)(39-96) \\
2 / 3^{\star}\end{array}$ & $\begin{array}{l}0 \cdot 73(0 \cdot 14)(0 \cdot 5-1 \cdot 0) \\
2 / 3^{\star}\end{array}$ & $\begin{array}{l}2 / 16 \dagger \\
56(6)(46-65)\end{array}$ & $\begin{array}{l}4 / 16 \\
0 / 3\end{array}$ \\
\hline $\begin{array}{l}\text { Group 2: } \\
\text { AS } \\
\text { AI }\end{array}$ & $\begin{array}{l}5 \\
4\end{array}$ & $\begin{array}{l}62(8)(52-72) \\
52(11)(36-62)\end{array}$ & $\begin{array}{l}2 \cdot 3(0 \cdot 4)(2-3) \\
2 \cdot 3(0 \cdot 5)(2-3)\end{array}$ & $\begin{array}{l}71(21)(38-93) \\
1 / 4^{\star}\end{array}$ & $\begin{array}{l}0.54(0 \cdot 17)(0.3-0.7) \\
1 / 4^{\star}\end{array}$ & $\begin{array}{l}2 / 5 \dagger \\
64(8)(58-75)\end{array}$ & $\begin{array}{l}3 / 5 \\
0 / 4\end{array}$ \\
\hline $\begin{array}{l}\text { Group 3: } \\
\text { AS } \\
\text { AI }\end{array}$ & $\begin{array}{r}10 \\
6\end{array}$ & $\begin{array}{l}58(9)(39-69) \\
54(6)(46-58)\end{array}$ & $\begin{array}{l}2.3(0.4)(2-3) \\
2.2(0.5)(1.5-3)\end{array}$ & $\begin{array}{l}69(12)(54-97) \\
0 / 6^{\star}\end{array}$ & $\begin{array}{l}0 \cdot 76(0 \cdot 19)(0 \cdot 5-1 \cdot 0) \\
0 / 6^{\star}\end{array}$ & $\begin{array}{l}2 / 10 \dagger \\
51(6)(47-55)\end{array}$ & $\begin{array}{l}4 / 10 \S \\
3 / 6\end{array}$ \\
\hline
\end{tabular}

AI, aortic insufficiency; AS, aortic stenosis; AVA, aortic valve area; $f_{\mathrm{so}}$ : aortic regurgitation fraction; $f_{\mathrm{mi}}$ : mitral regurgitation fraction; mean $A V$ gradient, mean aortic valve pressure gradient; NYHA, New York Heart Association.

$\star$ Combined aortic valve disease with predominant insufficiency (AVA $>1.0 \mathrm{~cm}^{2}$ ); †combined aortic valve disease with predominant aortic stenosis $($ AVA $\leqslant 1.0$ $\left.\mathrm{cm}^{2}\right)$; †mitral insufficiency $<15 \%$; §one patient with $\mathrm{f}_{\mathrm{mi}}$ of $38 \%$ (determined by thermodilution).

Table 2 Comparison of haemodynamic and angiographic data (mean (SD)) in controls and patients with aortic valve disease without (group 1 ) and with (group 2) left ventricular dysfunction and in postoperative patients (group 3)

\begin{tabular}{|c|c|c|c|c|c|c|c|c|c|c|c|}
\hline Group & $\begin{array}{l}\text { Number of } \\
\text { patients }\end{array}$ & $\begin{array}{l}E F \\
(\%)\end{array}$ & $\begin{array}{l}E D V I \\
\left(m l / m^{2}\right)\end{array}$ & $\begin{array}{l}h_{e d} \\
(\mathrm{~cm})\end{array}$ & $\begin{array}{l}\operatorname{LMMI} \\
\left(\mathrm{g} / \mathrm{m}^{2}\right)\end{array}$ & $\begin{array}{l}\text { LVSP } \\
(m m \mathrm{Hg})\end{array}$ & $\begin{array}{l}A o_{\text {ssst }} \\
(m m \mathrm{Hg})\end{array}$ & $\begin{array}{l}\text { LVEDP } \\
(m m \mathrm{Hg})\end{array}$ & $\begin{array}{l}C I \\
\left(l / \min \times m^{2}\right)\end{array}$ & $\begin{array}{l}S_{\text {ed }} \\
\left(d y n \times 10^{3} / \mathrm{cm}^{2}\right)\end{array}$ & $\begin{array}{l}S_{\text {pak }} \\
\left(d y n \times 10^{3} / \mathrm{cm}^{2}\right)\end{array}$ \\
\hline $\begin{array}{l}\text { Controls } \\
\text { Group 1 } \\
\text { Group 2 } \\
\text { Group } 3\end{array}$ & $\begin{array}{r}6 \\
19 \\
9 \\
16\end{array}$ & $\begin{array}{l}71(5) \\
65(5) \\
45(5) \\
67(7)\end{array}$ & $\begin{array}{r}95(20) \\
118(30) \\
146(45) \\
91(12)\end{array}$ & $\begin{array}{l}0.70(0.07) \\
1.16(0.11) \\
1.11(0.17) \\
0.93(0.13)\end{array}$ & $\begin{array}{r}77(14) \\
163(42) \\
170(42) \\
100(18)\end{array}$ & $\begin{array}{l}117(18) \\
207(37) \\
170(54) \\
133(19)\end{array}$ & $\begin{array}{l}122(10) \\
138(21) \\
124(17) \\
133(19)\end{array}$ & $\begin{array}{l}10(3) \\
14(4) \\
20(11) \\
7(4)\end{array}$ & $\begin{array}{l}4.3(1.0) \\
3.2(0.4) \\
2.8(0.5) \\
3.5(0.8)\end{array}$ & $\begin{array}{l}50(9) \\
39(13) \\
64(35) \\
25(13)\end{array}$ & $\begin{array}{l}437(60) \\
470(83) \\
478(111) \\
373(74)\end{array}$ \\
\hline $\begin{array}{l}\text { p values: } \\
\text { Controls } 2 \\
\text { Controls } v \\
\text { Controls } v \\
\begin{array}{lll}1 & v 2 \\
1 & v 3 \\
2 & v 3\end{array}\end{array}$ & $\begin{array}{l}v 1 \\
v 2 \\
v 3\end{array}$ & $\begin{array}{l}\text { NS } \\
<0.001 \\
\text { NS } \\
<0.001 \\
\text { NS } \\
<0.001\end{array}$ & $\begin{array}{l}\text { NS } \\
<0.02 \\
\text { NS } \\
\text { NS } \\
\text { NS } \\
<0.001\end{array}$ & $\begin{array}{l}<0.001 \\
<0.001 \\
\text { NS } \\
\text { NS } \\
<0.001 \\
\text { NS }\end{array}$ & $\begin{array}{l}<0.001 \\
<0.001 \\
\text { NS } \\
\text { NS } \\
<0.001 \\
<0.001\end{array}$ & $\begin{array}{l}<0.001 \\
<0.05 \\
\text { NS } \\
\text { NS } \\
<0.001 \\
\text { NS }\end{array}$ & $\begin{array}{l}\text { NS } \\
\text { NS } \\
\text { NS } \\
\text { NS } \\
\text { NS } \\
\text { NS }\end{array}$ & $\begin{array}{l}\text { NS } \\
<0.05 \\
\text { NS } \\
\text { NS } \\
<0.02 \\
<0.001\end{array}$ & $\begin{array}{l}\text { NS } \\
<0.01 \\
\text { NS } \\
\text { NS } \\
\text { NS } \\
\text { NS }\end{array}$ & $\begin{array}{l}\text { NS } \\
\text { NS } \\
\text { NS } \\
<0.02 \\
\text { NS } \\
<0.001\end{array}$ & $\begin{array}{l}\text { NS } \\
\text { NS } \\
\text { NS } \\
\text { NS } \\
<0.01 \\
<0.05\end{array}$ \\
\hline
\end{tabular}

$\mathrm{Ao}_{\text {syu }}$, systolic aortic pressure; CI, cardiac index; EDVI, left ventricular end diastolic volume index; EF, biplane left ventricular ejection fraction; $\mathrm{h}_{\text {ed }}$, end diastolic left ventricular wall thickness; LMMI, left ventricular muscle mass index; LVEDP, left ventricular end diastolic pressure; LVSP, left ventricular systolic pressure; $S_{e d}$, end diastolic left ventricular circumferential wall stress; $S_{\text {peak }}$, peak systolic left ventricular circumferential wall stress.

\section{CORONARY DYNAMICS IN PREOPERATIVE} PATIENTS AND CONTROLS (TABLE 3 AND FIGURES 1 AND 2)

Coronary sinus pressure was similar in the four groups. However, mean aortic pressure and mean coronary perfusion pressure (that is, mean aortic minus mean coronary sinus pressure) in the patients in group 2 (85 and 80 $\mathrm{mm} \mathrm{Hg}$ ) were slightly lower than in the postoperative patients $(100$ and $97 \mathrm{~mm} \mathrm{Hg}$, $\mathrm{p}<0.05)$. Heart rate was higher in group 2 than groups 1 and 3 . There were no differences among the four groups in coronary sinus blood flow, coronary resistance per $100 \mathrm{~g}$ muscle mass, haemoglobin concentration, the arteriovenous difference in oxygen content, and the left ventricular oxygen consumption per $100 \mathrm{~g}$ muscle mass.

The relation between myocardial oxygen consumption per $100 \mathrm{~g}$ and the systolic stressrate product in controls and in patients in group 1 was compared by regression analysis of covariance. The regression line for group 1 was below that of controls (fig 1 ). In a second step we considered left ventricular muscle mass index as continuous variable and we performed a multiple regression analysis of the data obtained by pooling controls and patients of group $1(n=25)$. In agreement with the result of the covariance analysis the stress-rate product $(p<0.02)$ was positively and left ventricular muscle mass index $(p<0.003)$ was negatively correlated with the myocardial oxygen consumption per $100 \mathrm{~g}$ of myocardium $(r=0.65)$. Thus at a given stress-rate product the myocardial oxygen consumption per $100 \mathrm{~g}$ of the hypertrophied ventricles with a normal ejection fraction was significantly lower than in non-hypertrophied ventricles with a normal ejection fraction.

When preoperative patients with left ventricular hypertrophy and a preserved ejection fraction (group 1) were compared with patients with a decreased ejection fraction (group 2) regression analysis of covariance showed a regression line for group 1 above that for group 2 (fig 2). When the left ventricular ejection fraction was regarded as a continuous variable in the pooled groups 1 and $2(n=28)$, multiple regression analysis showed that the stress-rate product $(p<0.001)$ and the ejection fraction $(p<0.03)$ were positively correlated with myocardial oxygen consumption per $100 \mathrm{~g}$ $(r=0.64)$. This indicates a significant reduction in the myocardial oxygen consumption per $100 \mathrm{~g}$ at a given stress-rate product in hypertrophied ventricles with reduced contractility compared with hypertrophied ventricles of normal contractility - that is, with a normal ejection fraction.

In group 1 the subgroups of patients with aortic stenosis $(n=16)$ and insufficiency $(\mathbf{n}=3)$ had similar myocardial oxygen consumptions per $100 \mathrm{~g}(10.0(3.3) v 12.3(4 \cdot 7) \mathrm{ml}$ 
Table 3 A comparison of coronary dynamics (mean (1SD)) in controls and patients with aortic valve disease without (group 1 ) and with (group 2) left ventricular dysfunction and in postoperative patients (group 3)

\begin{tabular}{|c|c|c|c|c|c|c|c|c|c|}
\hline Group & $\begin{array}{l}\text { Number of } \\
\text { patients }\end{array}$ & $\begin{array}{l}\text { MAP } \\
(m m \mathrm{Hg})\end{array}$ & $\begin{array}{l}\text { CSP } \\
(m m \mathrm{Hg})\end{array}$ & $\begin{array}{l}\text { HR } \\
\text { (beats/min) }\end{array}$ & $\begin{array}{l}\text { CSBF } / 100 \mathrm{~g} \\
(\mathrm{ml} / \mathrm{min} \times 100 \mathrm{~g})\end{array}$ & $\begin{array}{l}C R / 100 \mathrm{~g} \\
(\mathrm{~mm} \mathrm{Hg} \times \min \times 100 \mathrm{~g} / \mathrm{ml})\end{array}$ & $\begin{array}{l}H b \\
(g \%)\end{array}$ & $\begin{array}{l}A V D-o_{2} \\
(\text { vol\% })\end{array}$ & $\begin{array}{l}\mathrm{MVO} \mathrm{O}_{2} / 100 \mathrm{~g} \\
\left(\mathrm{ml} \mathrm{O} \mathrm{O}_{2} / \mathrm{min}\right)\end{array}$ \\
\hline $\begin{array}{l}\text { Controls } \\
\text { Group 1 } \\
\text { Group } 2 \\
\text { Group } 3\end{array}$ & $\begin{array}{r}6 \\
19 \\
9 \\
16\end{array}$ & $\begin{array}{c}98(8) \\
92(12) \\
85(1) \\
100(12)\end{array}$ & $\begin{array}{l}4(1) \\
4(2 \cdot 2) \\
4(3 \cdot 0) \\
3(1 \cdot 6)\end{array}$ & $\begin{array}{l}69(11) \\
70(9) \\
83(12) \square \\
70(12) \square\end{array}$ & $\begin{array}{l}120(18) \\
86(29) \\
79(31) \\
91(39)\end{array}$ & $\begin{array}{l}0.80(0.10) \\
1.13(0.36) \\
1.15(0.44) \\
1.24(0.49)\end{array}$ & $\begin{array}{l}14.2(0.9) \\
13.7(1.3) \\
13.8(1.4) \\
14.4(0.9)\end{array}$ & $\begin{array}{l}12 \cdot 0(1 \cdot 1) \\
12 \cdot 2(1 \cdot 2) \\
12 \cdot 2(1 \cdot 5) \\
12 \cdot 2(0 \cdot 8)\end{array}$ & $\begin{array}{r}14 \cdot 3(2 \cdot 3) \\
10 \cdot 4(3.5) \\
9 \cdot 5(3.0) \\
11 \cdot 1(4.6)\end{array}$ \\
\hline
\end{tabular}

AVD- $\mathrm{O}_{2}$, arteriocoronary sinus difference in oxygen content; $\mathrm{CR} / 100 \mathrm{~g}$, coronary resistance per $100 \mathrm{~g}$ muscle mass; CSBF/100 g, coronary sinus blood flow per $100 \mathrm{~g}$ muscle mass; CSP, coronary sinus pressure; $\mathrm{Hb}$, haemoglobin; HR, heart rate; MAP, mean aortic pressure; $\mathrm{MVo}_{2} / 100 \mathrm{~g}$, myocardial oxygen consumption per $100 \mathrm{~g}$ muscle mass.

${ }_{\star}^{\star} \mathrm{p}<0.05$.

Figure 1 Regression lines (common slope 0.00028 ml $\mathrm{O}_{2} \times \mathrm{cm}^{2} / 10^{3} \mathrm{dyn}$ $\times 100 \mathrm{~g}$ ) between left ventricular myocardial oxygen consumption per $100 \mathrm{~g}$ muscle mass $\left(\mathrm{MVO}_{2}\right)$ and the stressrate product (HR $\times$ $\left.S_{\text {peak }}\right)$ in controls $(n=6)$ and patients with aortic valve disease and preserved left ventricular function (group 1, $n=19$ ). At a given stress-rate product myocardial oxygen consumption per $100 \mathrm{~g}$ muscle mass in group 1 was lower than in the controls (intercept on the $\mathrm{MVO}$ axis, 1.0 ข $6.1 \mathrm{ml} \mathrm{O}_{2} / \mathrm{min}$ $\times 100 \mathrm{~g}, \mathrm{p}<0.001$ ).

Figure 2 Regression lines (common slope 0.00025 ml $\mathrm{O}_{2} \times \mathrm{cm}^{2} / 10^{3} \mathrm{dyn}$ $\times 100 \mathrm{~g}$ ) between left ventricular myocardial oxygen consumption per $100 \mathrm{~g}$ muscle mass $\left(\mathrm{MVO}_{2}\right)$ and the stressrate product $(H R \times$ $S_{\text {peak }}$ ) in patients with aortic valve disease and normal (group $1, n=19$ ) and reduced (group 2 , $n=9)$ ejection fraction. At a given stress-rate product myocardial oxygen consumption per $100 \mathrm{~g}$ muscle mass in group 2 patients was lower than in group 1 (intercept, $-0.4 \mathrm{v}$ $1.0 \mathrm{ml} \mathrm{O} / \mathrm{min} \times 100 \mathrm{~g}$ $p<0.05$ ).
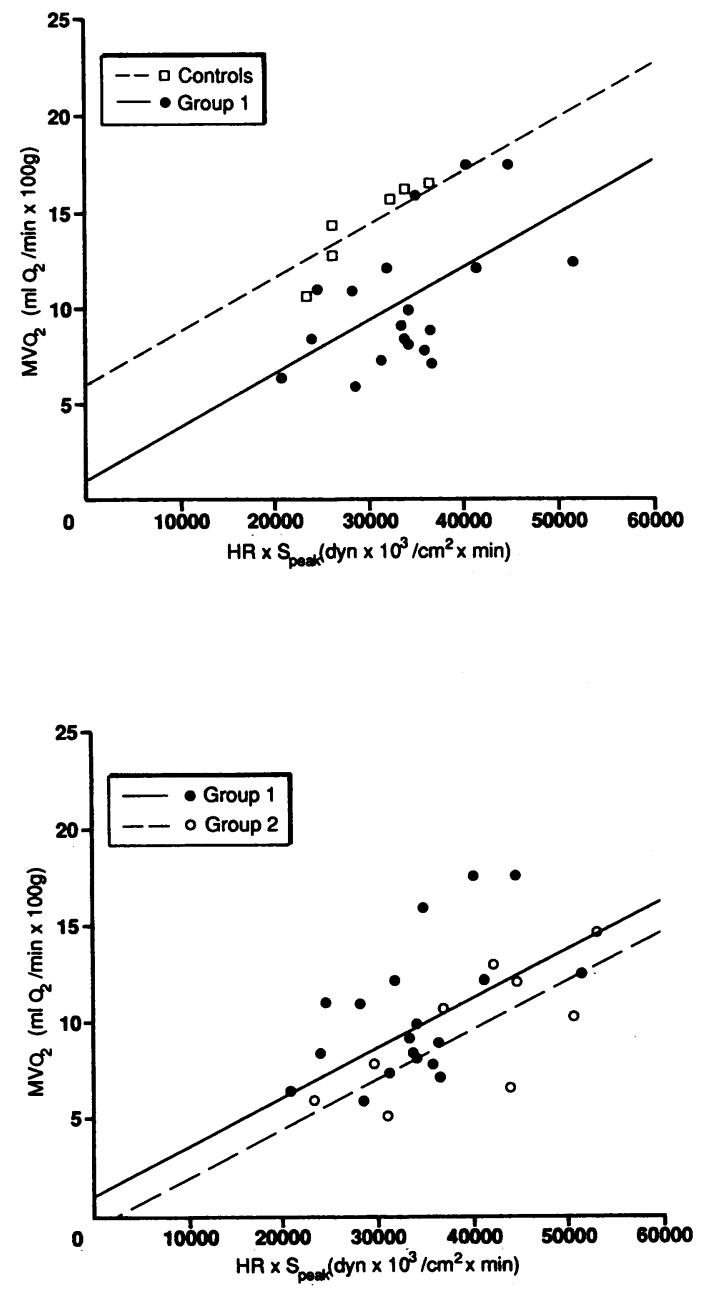

$\mathrm{O}_{2} / \mathrm{min} \times 100 \mathrm{~g}$ ) and there were no differences in the determinants of myocardial oxygen consumption-that is, the stress-rate product, left ventricular ejection fraction, and left ventricular muscle mass index (33671 v 35643 dyn $\times 10^{3} / \mathrm{cm}^{2} \times \min ; 65 v 66 \%, 164 v 156$ $\left.\mathrm{g} / \mathrm{m}^{2}\right)$. Similarly, in group 2 these variables were similar in the patients with aortic stenosis $(\mathrm{n}=5)$ and insufficiency $(\mathrm{n}=4)(10 \cdot 1 v 8.8 \mathrm{ml}$ $\mathrm{o}_{2} / \min \times 100 \mathrm{~g} ; 41412 v 37217$ dyn $\times 10^{3} /$ $\mathrm{cm}^{2} \times \min ; 46$ v 44\%; 182 v $155 \mathrm{~g} / \mathrm{m}^{2}$ respectively).

HAEMODYNAMICS AND CORONARY DYNAMICS IN THE POSTOPERATIVE GROUP (TABLES 1 AND 4, FIG 3)

The postoperative patient group included

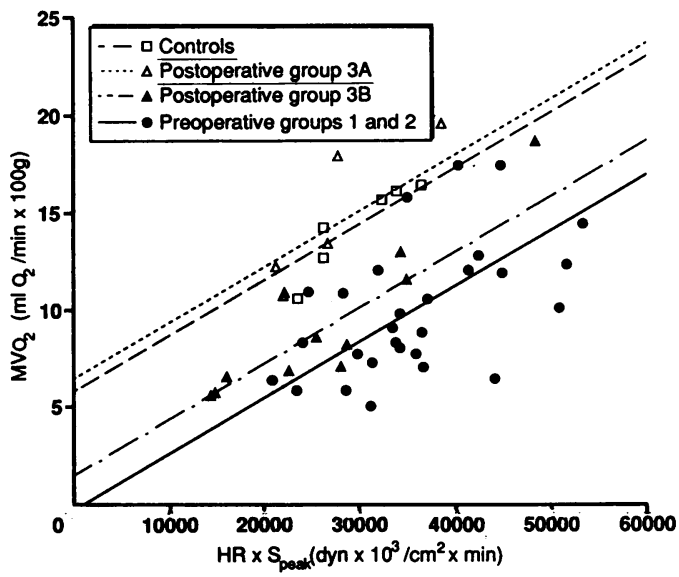

Figure 3 Regression lines (common slope $0.00028 \mathrm{ml}$ $\mathrm{O}_{2} \times \mathrm{cm}^{2} / 10^{3} \mathrm{dyn} \times 100 \mathrm{~g}$ ) between left ventricular myocardial oxygen consumption per $100 \mathrm{~g}$ muscle mass $\left(\mathrm{MVO}_{2}\right)$ and the stress-rate product $\left(\mathrm{HR} \times \mathrm{S}_{\text {peak }}\right)$ in controls $(n=6)$, in two postoperative patient groups (group $3 A, n=6$ and group $3 B, n=10$ ) and in preoperative patients (groups 1 and $2, n=28$ ). At a given stress-rate product myocardial oxygen consumption per $100 \mathrm{~g}$ in preoperative patients was lower than in the controls (intercept: $-0.2 \mathrm{v} 5.8 \mathrm{ml} \mathrm{O}_{2} / \mathrm{min} \times 100 \mathrm{~g}$, $p<0.01)$. The regression line of myocardial oxygen consumption per $100 \mathrm{~g}$ versus the stress rate product in the postoperative group $3 B$ was located between that of the controls (intercept, $1.6 \mathrm{v} 5.8 \mathrm{ml} \mathrm{O}_{2} / \mathrm{min} \times 100 \mathrm{~g}$, $p<0.02)$ and that of the preoperative patients (intercept, $1.6 \mathrm{v}-0.2 \mathrm{ml} \mathrm{O}_{2} / \mathrm{min} \times 100 \mathrm{~g}$, not significant). In the postoperative group $3 A$ with complete regression of hypertrophy and normal contractility myocardial oxygen consumption per $100 \mathrm{~g}$ at a given stress-rate product was higher than in group $3 B$

(intercept, 6.6 v $1.6 \mathrm{ml} \mathrm{O}_{2} / \mathrm{min} \times 100 \mathrm{~g}, \mathrm{p}<0.01$ ) and did not differ from that in the controls.

patients who had presented with normal or abnormal left ventricular function before operation. Therefore, the preoperative data available for group 3 were compared with the pooled data of preoperative patients (groups 1 and 2). No differences were found in preoperative aortic valve area $\left(0.8 v 0.7 \mathrm{~cm}^{2}\right)$ and pressure gradient $(69 v 72 \mathrm{~mm} \mathrm{Hg})$ in patients with pure or predominant aortic stenosis. Similarly, no difference was found in preoperative regurgitation fraction $(51 v 58 \%)$ in the patients with pure or predominant aortic insufficiency.

Furthermore, the two patient populations had similar left ventricular ejection fractions, end diastolic volume indices, left ventricular muscle mass indices, left ventricular systolic and end diastolic pressures, heart rates, and cardiac indices. Only the left ventricular end diastolic wall thickness in the pooled pre- 
Table 4 Comparison between the pooled preoperative data (mean (SD)) of groups 1 and 2 and the preoperative and postoperative data of group 3

\begin{tabular}{|c|c|c|c|c|c|c|c|c|c|}
\hline Group & $n$ & $E F(\%)$ & $\begin{array}{l}E D V I \\
\left(m l / m^{2}\right)\end{array}$ & $h_{d d}(\mathrm{~cm})$ & $\underset{\left(\mathrm{g} / \mathrm{m}^{2}\right)}{\operatorname{LMMI}}$ & $\begin{array}{l}\text { LVSP } \\
(m m \boldsymbol{H} \mathbf{H})\end{array}$ & $\begin{array}{l}\text { LVEDP } \\
(\mathbf{m m ~ H g})\end{array}$ & $\begin{array}{l}\text { HR } \\
\text { (beats/min) }\end{array}$ & $\begin{array}{l}C I \\
\left(l / \min \times m^{2}\right)\end{array}$ \\
\hline Groups 1 and 2 & 28 & $59(11)$ & $127(37)$ & $1 \cdot 15(0.13)$ & $165(31)$ & $195(45)$ & $16(8)$ & $74(12)$ & $3.1(0.5)$ \\
\hline $\begin{array}{l}\text { Group 3 } \\
\text { Preoperative } \\
\text { Postoperative }\end{array}$ & $\begin{array}{l}16 \\
16\end{array}$ & $\begin{array}{l}58(13) \\
67(7)\end{array}$ & $\begin{array}{r}155(58) \\
92(12)\end{array}$ & $\begin{array}{l}1.04(0.16) \\
0.92(0.13)\end{array}$ & $\begin{array}{l}159(39) \\
100(18)\end{array}$ & $\begin{array}{l}173(41) \\
133(19)\end{array}$ & $\begin{array}{c}18(10) \\
7(4)\end{array}$ & $\begin{array}{l}69(12) \\
70(12)\end{array}$ & $\begin{array}{l}3.4(1.0) \\
3.5(0.8 \ddagger)\end{array}$ \\
\hline $\begin{array}{l}\text { p values: } \\
1+2 v 3 \text { preop }{ }^{\star} \\
1+2 v 3 \text { postop } \\
3 \text { preop } v 3 \text { postop } \dagger\end{array}$ & & $\begin{array}{l}\text { NS } \\
<0.01 \\
<0.001\end{array}$ & $\begin{array}{l}\text { NS } \\
<0.001 \\
<0.001\end{array}$ & $\begin{array}{l}<0.02 \\
<0.001 \\
<0.001\end{array}$ & $\begin{array}{l}\text { NS } \\
<0.001 \\
<0.001\end{array}$ & $\begin{array}{l}\text { NS } \\
<0.001 \\
<0.001\end{array}$ & $\begin{array}{l}\text { NS } \\
<0.001 \\
<0.001\end{array}$ & $\begin{array}{l}\text { NS } \\
\text { NS } \\
\text { NS }\end{array}$ & $\begin{array}{l}\text { NS } \\
\text { NS } \\
\text { NS } \ddagger\end{array}$ \\
\hline
\end{tabular}

$\mathrm{CI}$, cardiac index; EDVI, end diastolic volume index; EF, left ventricular biplane ejection fraction; $h_{\text {od }}$ left ventricular end diastolic wall thickness; HR, heart rate; LMMI, left ventricular muscle mass index; LVEDP, left ventricular end diastolic pressure; LVSP, left ventricular peak systolic pressure.

*Values obtained by unpaired $t$ test.

tValues obtained by paired $t$ test.

†n $=13$.

operative group was slightly higher than the preoperative wall thickness of group 3 (1.15 v $1.04 \mathrm{~cm}, \mathrm{p}<0.02$ ), reflecting the higher proportion of pressure-overloaded hearts in the pooled preoperative groups 1 and 2 (aortic stenosis $21 / 28$ ) compared with group 3 (aortic stenosis 10/16).

Postoperatively the group 3 patients showed a considerable improvement in haemodynamic variables compared with their preoperative data and that of the pooled preoperative groups 1 and 2. There was a reduction in the end diastolic volume index, left ventricular systolic pressure and end diastolic pressure, left ventricular end diastolic wall thickness, and muscle mass index. The left ventricular muscle mass index and the interval after successful aortic valve replacement were negatively correlated $(r=-0.50, p<0.05)$. The ejection fraction increased in group 3 after operation.

The relation between myocardial oxygen consumption per $100 \mathrm{~g}$ and the stress-rate product was compared among controls, patients in groups $3 \mathrm{~A}, 3 \mathrm{~B}$, and the pooled preoperative patients of groups 1 and 2 by analysis of covariance (fig 3 ). Similar regression lines were found for controls and postoperative patients with complete normalisation of left ventricular muscle mass and contractility (group 3A). These two regression lines were above that for the postoperative patients with incomplete postoperative normalisation (group 3B) and that of pooled preoperative patients (groups 1 and 2). Group 3B and preoperative patients (groups 1 and 2) again had similar regression lines.

Multiple regression analysis of the whole study population (50 measurements) showed that the stress-rate product $\left(\mathbf{H R} \times \mathrm{S}_{\text {pest }}\right.$, $p<0.0001$ ), left ventricular muscle mass index (LMMI, p < 0.002), and ejection fraction $(\mathrm{EF}, \mathrm{p}<0.03)$ were significant "explanatory" variables of myocardial oxygen consumption per $100 \mathrm{~g} \quad\left(\mathrm{MVo}_{2} / 100 \mathrm{~g}\right)$, $r=0.72$. The following equation was obtained (corresponding standard errors are given in parentheses):

$$
\begin{gathered}
\mathrm{MVO}_{2} / 100 \mathrm{~g}=-0.06+0.27(0.045) \\
\mathrm{HR} \cdot \mathrm{S}_{\text {peak }}-0.04(0.01) \mathrm{LMMI}+0.11 \\
(0.048) \mathrm{EF}
\end{gathered}
$$

where $\mathrm{MVo}_{2} / 100 \mathrm{~g}(\mathrm{ml} \mathrm{o} / \mathrm{min} \times 100 \mathrm{~g})$;
$\mathrm{HR} \cdot \mathrm{S}_{\text {peak }}\left(\mathrm{dyn} / \mathrm{cm}^{2} \times \mathrm{min}\right) ; \mathrm{LMMI}\left(\mathrm{g} / \mathrm{m}^{2}\right) ; \mathrm{EF}$ (\%).

The stress-rate product was not correlated with the left ventricular ejection fraction or muscle mass index; but there was a weak negative correlation between left ventricular ejection fraction and muscle mass index $(r=-0.48)$. In the stepwise regression the stress-rate product was the first variable entered into the equation $\left(r^{2}=0.22\right)$, then the left ventricular muscle mass index $\left(r^{2}=0.47\right)$, and finally $r^{2}$ increased to 0.52 when left ventricular ejection fraction was included. When multiple regression analysis was carried out with 32 measurements instead of 50, after patients with aortic valve disease who were older than 58 years (upper limit in the control group) were excluded, the stress-rate product (p $<0.0001$ ), left ventricular muscle mass index $(p<0.0005)$, and ejection fraction $(p<0.04)$ remained significant "explanatory" variables of myocardial oxygen consumption per $100 \mathrm{~g}$. Moreover, when age was introduced as an additional variable in the original multiple regression analysis (50 measurements) it was found not to be a significant determinant of myocardial oxygen consumption per $100 \mathrm{~g}$.

\section{Discussion}

RELATION BETWEEN MYOCARDIAL OXYGEN CONSUMPTION AND STRESS-RATE PRODUCT Traditionally, the tension-time index and heart rate are recognised as important determinants of myocardial oxygen consumption. ${ }^{318}$ Subsequent studies performed in animals ${ }^{319}$ and in humans $s^{120}$ identified left ventricular peak systolic wall stress and the integral of systolic wall stress $^{21}$ as major determinants of myocardial blood flow and oxygen consumption. From other studies performed in non-hypertrophied animal hearts it became evident that, contractility, as well as wall stress, has a major influence on the myocardial oxygen consumption. ${ }^{22}$ Therefore the purpose of the present study was to answer the following questions: first, whether in the chronically overloaded hypertrophied human heart myocardial oxygen consumption per $100 \mathrm{~g}$ is related to an analogue of the minute tension-time index - that is, the product of heart rate and peak systolic stress; second, how this relation is modified by chronic alterations 
in contractility or myocardial hypertrophy or both; and third, what effect regression of hypertrophy has on the relation between myocardial oxygen consumption per $100 \mathrm{~g}$ and the stressrate product.

In patients with aortic valve disease with left ventricular dysfunction and without, in postoperative patients, and in controls we found a significant correlation between the myocardial oxygen consumption per $100 \mathrm{~g}$ and the stressrate product. In addition to this major determinant of myocardial oxygen consumption per $100 \mathrm{~g}$ multiple regression analysis showed left ventricular hypertrophy and contractility were further factors that influenced myocardial oxygen consumption per $100 \mathrm{~g}$.

\section{MYOCARDIAL OXYGEN CONSUMPTION IN HYPERTROPHIED AND NON-HYPERTROPHIED VENTRICLES}

Our results indicate that myocardial oxygen consumption per $100 \mathrm{~g}$ is reduced in left ventricular hypertrophy. Multiple regression showed that the stress-rate product was positively and muscle mass index was negatively correlated with myocardial oxygen consumption per $100 \mathrm{~g}$. This result was confirmed when analysis of covariance (fig 1) showed that the regression line of the stressrate product and myocardial oxygen consumption per $100 \mathrm{~g}$ in group 1 was located below that of the controls. This finding has several possible explanations. First, reduced myocardial oxygen consumption per $100 \mathrm{~g}$ at a given level of overall left ventricular performance, represented by the stress-rate product, might be an intrinsic property of the hypertrophied cardiac muscle. Various investigations of human and animal hypertrophied myocardium $^{24-27}$ showed that enzymatic and ultrastructural changes develop as a consequence of hypertrophy and result in a slowing of cardiac contraction $^{28}$ and improved efficiency at the cellular level. A second explanation may relate to the definition of contractile state in the patients of group 1 . In concentric hypertrophy such as in aortic stenosis it is well known that the ejection fraction overestimates left ventricular fibre shortening because thickening of the hypertrophied wall in itself reduces the systolic cavity. ${ }^{29}$ Hence a normal ejection fraction does not exclude a slight reduction in contractility ${ }^{30}$ which in turn might have caused the decreased myocardial oxygen consumption per $100 \mathrm{~g}$. Finally, does the reduced myocardial oxygen consumption calculated per 100 gram of muscle mass really indicate a reduced oxygen consumption of the myocyte tissue? There is more interstitial tissue per 100 gram of left ventricular muscle mass in hypertrophied than in normal myocardium ${ }^{31}$ and interstitial tissue consumes less oxygen than myocyte tissue.

A lower myocardial oxygen consumption per $100 \mathrm{~g}$ at a given index of overall left ventricular performance represented by the stress-rate product suggests that the mechanical efficiency per volume unit of the hypertrophied nonfailing left ventricular myocardium is greater than that of the normal myocardium. Both Malik et $a l^{32}$ and Su-Fan et $a l^{4}$ reported that the mechanical efficiency of hypertrophied compensated canine left ventricles was greater than that of non-hypertrophied ventricles.

MYOCARDIAL OXYGEN CONSUMPTION IN DIFFERENT CONTRACTILE STATES

Johnson et al reported a close relation between coronary blood flow per beat and peak systolic stress $(r=0.97)$ in patients with aortic valve disease. ${ }^{1}$ However, no direct measurement of left ventricular contractility was performed in that study. Weiss et al investigated patients with hypertrophic and congestive cardiomyopathies and found that heart rate, mean velocity of circumferential fibre shortening, and peak systolic stress were the main factors influencing myocardial oxygen consumption; the influence of hypertrophy was not evaluated. ${ }^{20}$ Henry et al examined 14 patients with valve lesions, cardiomyopathies, and congenital heart diseases and emphasised the importance of the contractile state as a determinant of myocardial oxygen consumption. ${ }^{33}$ They did not standardise contractility per unit stress, however, thus neglecting stress as an additional determinant of the myocardial oxygen consumption. In accordance with these findings our study showed that the stress-rate product and muscle mass index were determinants of myocardial oxygen consumption and that the left ventricular ejection fraction was a third determinant of myocardial oxygen consumption/100 g (fig 2).

These results seem to be at variance with the findings of Strauer. ${ }^{34} \mathrm{He}$ described a low myocardial oxygen consumption in low stress ventricles with preserved ejection fraction and adequate hypertrophy; in contrast, in high stress ventricles with excessive hypertrophy he found a high myocardial oxygen consumption accompanied by a reduced ejection fraction. In that study slight changes in contractility were associated with considerable changes in afterload. In the absence of changes in contractility peak systolic stress becomes the main determinant of myocardial oxygen consumption. In our group 2 patients the decrease in ejection fraction was not the effect of excessive overloading (as in Strauer's study) because peak systolic stress was not different in controls, group 1, and group 2. Thus differences in contractility must have been present. In the group 2 patients mechanical efficiency was likely to be higher and cardiac index was lower than in the controls, which shows that hypertrophied ventricles in which contractility is depressed are unable to transfer the generated energy to the circulation despite an improved efficiency. This paradox was recently discussed by $\mathrm{Su}-\mathrm{Fan}$ et al. ${ }^{4}$ They reported that after induction of hypertrophy in canine left ventricles by a combined aortic valve lesion the hypertrophied hearts showed better oxygen utilisation than the controls, but the pressure work increased without a concomitant increase in cardiac output.

MYOCARDIAL OXYGEN CONSUMPTION IN THE POSTOPERATIVE STATE

In the postoperative patients there was a con- 
siderable improvement in left ventricular haemodynamic function at rest, and regression, albeit not complete, of myocardial hypertrophy. But what about the postoperative interrelations of myocardial oxygen consumption with peak systolic stress, heart rate, contractility, and muscle mass? Kawachi et al reported that in patients with aortic incompetence after operation the peak systolic stress decreased, heart rate remained unchanged, and the ejection fraction increased. ${ }^{35}$ The postoperative increase of both the coronary sinus blood flow per beat per $100 \mathrm{~g}$ muscle mass and the myocardial oxygen consumption per beat per $100 \mathrm{~g}$ was attributed to the postoperative improvement in contractility. To evaluate the influence of postoperative changes in hypertrophy and contractility on myocardial oxygen consumption its relation to the stress-rate product was examined in controls, patients of groups $3 \mathrm{~A}$ and $3 \mathrm{~B}$, and the pooled preoperative patients of groups 1 and 2 . As fig 3 shows the regression line of group 3B was located between that of the controls and the preoperative patients, but was not significantly different from that of the preoperative group. The regression line of group $3 \mathrm{~A}$ was not different from that of the controls. Thus the postoperative patients with full recovery of contractility and complete regression of left ventricular hypertrophy showed that the changes in myocardial oxygen consumption per $100 \mathrm{~g}$ and myocardial efficiency were completely reversible.

\section{LIMITATIONS OF THE STUDY}

In this study the preoperative patients were divided into two groups based on the assessment of contractility, irrespective of the type of the haemodynamic burden that caused the left ventricular hypertrophy. Differences in several adaptational mechanisms between pressure and volume overload have been reported. ${ }^{29}$ However, aortic insufficiency cannot be considered as pure volume load and the degree of left ventricular hypertrophy is known to correlate with the total power requirements, whatever the type of overload. ${ }^{46}$ Furthermore, Johnson et al reported that the relation between the total load and the myocardial oxygen consumption per $100 \mathrm{~g}$ was the same when either aortic stenosis or insufficiency was present. ${ }^{1} \mathrm{We}$ too did not find any difference in myocardial oxygen consumption per $100 \mathrm{~g}$ or its determinants (that is, the stress-rate product, left ventricular ejection fraction, and muscle mass index) in patients with aortic stenosis and patients with aortic insufficiency (groups 1 and 2 ). This is why we do not think that our results were biased by the mixture of aortic valve lesions in each group.

Thermodilution techniques were used to measure total coronary sinus blood flow. Although this method does not measure perfusion in specific transmural layers or different ventricular regions or rapid changes in coronary blood flow, ${ }^{37}$ Ganz et al found a good correlation between coronary sinus flow measured by this technique and by the timed collection of coronary venous blood. ${ }^{14}$ Moreover, transmural distribution of blood flow at rest is likely to be homogeneous in both normal and hypertrophied ventricles whatever the type of overload. ${ }^{58}$

In all patient groups the relation between the stress-rate product and the myocardial oxygen consumption per $100 \mathrm{~g}$ was significant, though the correlation particularly in groups 1,2 , and 3 was not as close as in studies of paced canine ventricles. $^{1921}$ These differences can be explained at least in part by the following mechanisms: first, by the non-simultaneous measurement of haemodynamic function and the myocardial oxygen consumption in some patients; second, by the different degree of interstitial fibrosis, ${ }^{31}$ which we did not take into account; and third, by the likelihood that within the two groups with preserved and reduced contractility there was still considerable heterogeneity of contractility. Moreover we recognise the limitations of peak systolic stress as an index of the mean generated stress during ventricular systole, which would have been a measure more closely reflecting the classic tension-time index.

We thank Dr R Helfenstein for statistical advice and calculations. This work was supported by the Swiss National Science Foundation.

1 Johnson LL, Sciacca RR, Ellis K, Weiss MB, Cannon PJ. Reduced left ventricular myocardial blood flow per unit mass in aortic stenosis. Circulation 1978;57:582-90.

2 Trenouth RS, Phelps NC, Neil WA. Determinants of left ventricular hypertrophy and oxygen supply in chronic ventricular hypertrophy and oxygen supply in

3 Braunwald $\mathbf{E}$. Control of myocardial oxygen consumption. Am J Cardiol 1971;27:416-32.

$4 \mathrm{Su}-\mathrm{Fan} \mathrm{Q}$, Brum JM, Bove AA. Energy production, $\mathrm{O}_{2}$ con-Fan Q, Brum $\mathrm{M}$, Bove AA. Energy production, $\mathrm{O}_{2}$ aortic valve disease. Am J Physiol 1987;252:243-51.

5 Gasch WH, Zile MR, Hoshino PK, Apstein CS, Blaustein AS. Stress-shortening relations and myocardial blood flow in compensated and failing canine hearts with pressureoverload hypertrophy. Circulation 1989;79:872-83.

6 Thomas DP, Phillips SJ, Bove AA. Myocardial morphology and blood flow distribution in chronic volume-overload hypertrophy in dogs. Basic Res Cardiol 1984;79:379-88.

7 Bortone AS, Hess OM, Eberli FR, Nonogi H, Marolf AP, Grimm J, et al. Abnormal coronary vasomotion during exercise in patients with normal coronary arteries and reduced coronary flow reserve. Circulation 1988;79: 516-27.

8 Eichhorn P, Grimm J, Koch R, Hess O, Carroll J, Krayenbuehl HP. Left ventricular relaxation in patients with left ventricular hypertrophy secondary to aortic valve disease. Circulation 1982;65:1395-404.

9 Huber D, Grimm J, Koch R, Krayenbuehl HP. Determinants of ejection performance in aortic stenosis. Circulation 1981;64:126-34.

10 Dodge HT, Sandler H, Ballew DW, Lord JD. The use of biplane angiocardiography for the measurement of left biplane angiocardiography for the measurement of left

11 Rackley CE, Dodge HT, Coble YD, Hay RE. A method for determining left ventricular mass in man. Circulation determining left ventricular mass in man. Circulation 1964;29:666-71.

12 Sandler H, Dodge HT. Left ventricular tension and stress in man. Circ Res 1963;13:91-104.

13 Gaasch WH, Battle WE, Oboler AA, Banas JS, Levine HJ. Left ventricular stress and compliance in man with special reference to normalized ventricular function curves. Circulation 1972;45:746-62.

14 Ganz W, Tamura K, Marcus HS, Donoso R, Yoshida S, Swan HJC. Measurement of coronary sinus blood flow by continuous thermodilution in man. Circulation 1971;44:181-95.

15 Mathey DG, Chatteriee K, Tyberg JV, Lekven J, Brundage $B$, Parmley WW. Coronary sinus reflux: a source of error in the measurement of thermodilution coronary sinus flow. Circulation 1978;57:778-86.

16 Foult JM, Nitenberg A. Dipyridamole versus intracoronary injection of contrast medium for the evaluation of coronary reserve in man: a comparative study. Cathet Cardiovasc Diagn 1986;12:304-10.

17 Neter J, Wasserman W, Kutner JH. Applied linear statistical models. 2nd ed. Homewood, Illinois: Irwin, 1985:856-73.

18 Sarnoff SJ, Braunwald E, Welch GH, Case RB, Stainsby WN, Macruz R. Hemodynamic determinants of oxygen .

然


consumption of the heart with special reference to the conion-time index. Am J Physiol 1958;192:148-56.

19 McDonald RH Jr, Taylor RR, Cingolani HE. Measurement of myocardial developed tension and its relation to oxygen consumption. Am J Physiol 1966;211:667-73.

20 Weiss MB, Ellis K, Sciacca RR, Johnson LL, Schmidt DH, Cannon PJ. Myocardial blood flow in congestive and hypertrophic cardiomyopathy. Circulation 1976;54 484-94.

21 Weber KT, Janicki JS, Myocardial oxygen consumption: the role of wall force and shortening. Am J Physio 1977;233:421-30.

22 Graham TP Jr, Covell JW, Sonnenblick EH, Ross J Jr, Braunwald $\mathrm{E}$. Control of myocardial oxygen consumption: relative influence of contractile state and tension tion: relative influence of contractile state
development. J Clin Invest $1968 ; 47: 375-85$.

23 Downey JM. Myocardial contractile force as a function of coronary blood flow. Am J Physiol 1976;230:1-6.

24 Kozloyskis PL, Fieber LA, Pruitt DK, Bailey BK, Smets MJD, Bassett Al, et al. Myocardial changes during the
Mozlovis MJD, Bassett Al, et al. Myocardial changes during the
progression of left ventricular pressure-overload by renal progression of left ventricular pressure-overload by renal hypertension or aortic constriction: myosin, myosin ATPase

25 Kjeldsen K, Bjerregaard P, Richter EA, Block Thomsen PE, Norgaard $A$. $\mathrm{Na}^{+} / \mathrm{K}^{+}$-ATPase concentration in rodent and human heart and skeletal muscle: apparent relation to muscle performance. Cardiovasc Res 1988;22:95-100.

26 Peters TJ, Wells G, Oakley CM, Brooksby IAB, Jenkins BS, Webb-Peploe MM, et al. Enzymic analysis of endomyocardial biopsy specimens from patients with cardiomyopathies. Br Heart J 1977;39:1333-9.

27 Ferrans VJ. Human cardiac hypertrophy: structural aspects. Eur Heart J 1982;3(suppl A):15-27.

28 Swynghedauw B. Remodelling of the heart in response to chronic mechanical overload. Eur Heart $J$ 1989;10: 935-43.

29 Krayenbuehl HP, Hess O, Hirzel H. Pathophysiology of the hypertrophied heart in man. Eur Heart $J$ 1982;3(suppl A): $125-31$

30 Krayenbuehl HP, Hess OM, Ritter M, Monrad ES, Hoppeler $H$. Left ventricular systolic function in aortic stenosis. Eur Heart J 1988;9(suppl E):19-23.

31 Krayenbuehl HP, Hess OM, Monrad ES, Schneider J, Mall $G$, Turina $M$. Left ventricular myocardial structure in aortic valve disease before, intermediate, and late after aortic valve repalcement. Circulation 1989;79:744-55.

32 Malik AB, Abe T, O'Kane H, Geha AS. Cardiac function, coronary flow, and oxygen consumption in stable left ventricular hypertrophy. Am J Physiol 1973;225:186-91.

33 Henry PD, Eckberg D, Gault JH, Ross J Jr. Depressed inotropic state and reduced myocardial oxygen consumpinotropic state and reduced myocardial oxygen consum

tion in the human heart. Am J Cardiol 1973;31:300-6.
34 Strauer BE. Myocardial oxygen consumption in chronic heart disease: role of wall stress, hypertrophy and coronary reserve Am J Cardiol 1979;44:730-40.

35 Kawachi K, Kawashima Y, Kitamura S, Mori T, Hirose $\mathrm{H}$, Nakano $S$, et al. Coronary sinus blood flow and myocardial oxygen consumption after valve replacement for aortic insufficiency. Ann Thorac Surg 1986;42:86-9.

36 Baxley WA, Dodge HT, Rackley CE, Sandler H, Pugh D. Left ventricular mechanical efficiency in man with heart disease. Circulation 1977;55:564-8.

37 Marcus ML, Wilson RF, White CW. Methods of measurement of myocardial blood flow in patients: a critical review. Circulation 1987;76:245-53.

38 Breisch EA, Houser SR, Carey RA, Spann JF, Bove AA. Myocardial blood flow and capillary density in chronic pressure overload of feline left ventricle. Cardiovasc Res 1980;14:469-75. 